\title{
Increased incidence of sporadic Creutzfeldt-Jakob disease in the age groups between 70 and 90 years in Belgium
}

\author{
B. Van Everbroeck ${ }^{1}$, A. Michotte ${ }^{2}$, R. Sciot ${ }^{3}$, C. Godfraind ${ }^{4}$, M. Deprez ${ }^{5}$, S. Quoilin ${ }^{6}$, J.-J. Martin ${ }^{1} \&$ P. Cras ${ }^{1}$ \\ ${ }^{1}$ Born-Bunge Institute (BBI), University of Antwerp (UA), Campus Drie Eiken (CDE), Antwerp, Belgium; ${ }^{2}$ Department of Neuropathology, \\ Academic hospital, Free University of Brussels, Brussels, Belgium; ${ }^{3}$ Department of Pathology, Catholic University of Leuven, Leuven, \\ Belgium; \\ ${ }^{4}$ Pathology Laboratory, Catholic University of Louvain, Brussels, Belgium; \\ ${ }^{5}$ Laboratory of Neuropathology, University of Liège, Sart Tilman, Liège, Belgium; ${ }^{6}$ Institute of Public Health-Louis Pasteur, Brussels, \\ Belgium
}

\begin{abstract}
From 1998 a prospective surveillance study of Creutzfeldt-Jakob disease (CJD) has been initiated in Belgium. In addition to epidemiological data, information on cerebrospinal fluid biomarkers, prion protein gene and brain neuropathology was collected. From 1-1-1998 to 31-12-2004, 188 patients were referred to the surveillance system. In 85 patients a 'definite' diagnosis of sporadic CJD (sCJD) could be made, whereas 26 patients remained 'probable'. We further identified two unrelated patients with an E200K mutation, and two patients with a seven octapeptide repeat insertion in one family. In one patient a familial history was noted but genetic analysis was not performed. In 72 patients different final diagnoses were made, Alzheimer's disease being the most frequent $(N=20)$. The demographic parameters of the Belgian population were similar to those observed in the rest of Europe. We did notice a significantly increased age-specific incidence $\left(>6 / 10^{6} /\right.$ year) of sCJD patients between 70 and 90 years old in the period 2002-2004 compared to 1998-2001 and retrospectively obtained data $(1990-1997, p<0.01)$. We undertook a detailed clinical and biochemical analysis to investigate this increase but could not identify any reason other than an increased vigilance for the diagnosis. In conclusion, our study identified that in the past SCJD may have been underestimated in patients over age 70 although these patients are both clinically and neurobiochemically similar to the general SCJD phenotype.
\end{abstract}

Keywords : Diagnosis ; Epidemiology ; Prion disease ; Transmissible spongiform encephalopathy

\section{Introduction}

Sporadic Creutzfeldt-Jakob disease (sCJD) belongs to the group of the prion disorders or transmissible spongiform encephalopathies and it has always been presumed to have an incidence of 1 patient per million inhabitants per year [1]. The median age at death has consistently been reported to be between 60 and 65 years of age although a broad range, between 16 and 90 year old, has been recognised [2]. The clinical evolution of sCJD is variable but most commonly includes rapidly progressive dementia, motor disabilities, visual problems and eventually akinetic mutism, resulting in death within 1 year after onset. The definite diagnosis of CJD is based on the identification of the classical neuropathological triad: neuronal loss, gliosis and spongiform degeneration and recently of the identification prion protein deposition in the brain. A patient is diagnosed as 'possible' CJD if next to a fast progressive dementia with a duration of less then 2 years also 2 of the following signs can be identified: myoclonus, visual signs, extra-pyramidal or pyramidal signs, akinetic mutism and cerebellar signs. If periodic sharp wave complexes (PSWC) on the electroencephalogram (EEG) or the protein 14-3-3 test in cerebrospinal fluid (CSF) can be identified, patients are classified as 'probable' CJD.

After the description of variant CJD (vCJD) and the demonstration of a link with the epidemic of bovine spongiform encephalopathy [3], vigilance concerning the incidence of both vCJD and sCJD was increased, leading to the implementation of a Belgian CJD surveillance network.

A major development in the differential diagnosis of SCJD is the immunodetection of specific cerebrospinal fluid (CSF) biomarkers. Mostly the detection of the 14-3-3 protein or tau protein are used as they are reported to be the most sensitive and specific biomarkers for SCJD [4, 5]. In addition, decreased levels of full-length amyloidbeta $\left(\mathrm{A} \beta_{1-42}\right)$ can also be found in SCJD [6]. 
Recently a classification of sCJD according to the three genotypes of the methionine (M)/valine (V) polymorphism at the codon 129 of the prion gene (PrP129) and the two types of protease resistant prion protein $\left(\mathrm{PrP}^{\mathrm{res}}\right)$ has been described [7]. This classification, although still under fierce debate [8-10], is now widely used as an added parameter in SCJD epidemiology [11].

In this study we report the results of the first 7 years of our prospective surveillance study. Using classical and recently described analyses, we compared this series with other published series including a Belgian retrospective study of 95 definite sCJD patients $[12,13]$.

\section{Materials and methods}

The Belgian CJD surveillance is a collaborative study of the seven university centres of neurology/ neuropathology and the Institute of Public Health (IPH), which acts as the study coordinator and maintains the surveillance database. The university departments refer all patients which have a clinical diagnosis of 'probable' CJD to the IPH and eventually submit the definite, if possible the neuropathological, diagnosis to the database. Secondly, all Belgian 14-3-3 analyses are done in 1 centre (BBI, UA) and their database contains references to all patients in whom CJD was clinically suspected. This database was used as an important fail-safe to identify patients not investigated in the one of the university centres. All centres collected clinical data, CSF sample, DNA and brain tissue of patients in whom CJD was clinically suspected. In the past we had retrospectively collected clinical and neuropathological data on 95 definite SCJD patients [12, 13].

Demographic data on the Belgian population in the study period was obtained from the National Institute for Statistics (Belgium).

We used a western blot to analyse the 14-3-3 protein in CSF as previously described [14]. Other biomarkers such as tau protein and $\mathrm{A} \beta_{1-42}$ were measured with commercial enzyme linked immuno-assays (ELISA's) (Innogenetics nv, Ghent, Belgium) according to the manufacturer's instructions [14, 15].

Brain tissue was always fixed in $10 \%$ formaldehyde and paraffin embedded sections were made in each institute to confirm the clinical diagnosis as previously described $[13,16]$. When possible, one brain hemisphere was immediately frozen and stored at $-80^{\circ} \mathrm{C}$. At least two independent observers assessed the neuropathological lesions in the 12 selected areas [17, 18]. Inter-observer variability was below $10 \%$ for all patients (data not shown).

Sequencing of the prion protein gene (PRNP) and analysis of the Western blot type using a homogenate of the frontal cortex, were performed as previously described [19]. Patients with mutations in the PRNP were excluded from the analysis.

We used non-parametric tests (Mann-Whitney $U$, Kruskal-Wallis) and Fisher's exact probability to compare frequencies. A $p$-value of 0.05 was considered significant.

\section{Results}

\section{Demographic analysis}

From 1-1-1998 to 31-12-2004, 188 patients were referred to the Belgian surveillance system. A 'definite' diagnosis of SCJD could be made in 85 patients, whereas in 26 patients the diagnosis remained 'probable' as an autopsy was not possible. Neuropathological investigations and genetic analysis of the prion protein gene (PRNP) identified two unrelated patients with an E200K mutation and two patients in one family with a seven octapeptide repeat insertion in PRNP. In one patient a familial history was found but genetic analysis was not performed. In 72 patients CJD could be excluded. We observed that Alzheimer's disease $(N=20)$ and dementia with Lewy bodies $(N=12)$ were the most frequent alternative diagnoses.

The probable and definite SCJD patients had a median age at death of 66 years with a standard deviation (SD) of 10 years. The youngest patient was 32 year old at death, the oldest 88 . There was a small preponderance of males $(N=61)$ over females $(N=50)$ although large year-to-year variations were observed (Figure 1$)$. In our series, $86 \%$ of patients died within the first year after disease onset. All patients lived at least 1 month after disease onset with a median duration of 5.7 months (SD5.6, range 1-38 months). Only small variations were found when we compared our series to other published series in Europe (data not shown). 
Figure 1. The number of $s C J D$ in Belgium since 1998. The malelfemale ratio strongly varies from year to year (maximum 3.3 (1999), minimum 0.3 (2000)) but an almost equal average ratio (1.2) was obtained. We further identified an increased incidence in the last 3 years (2002-2004).

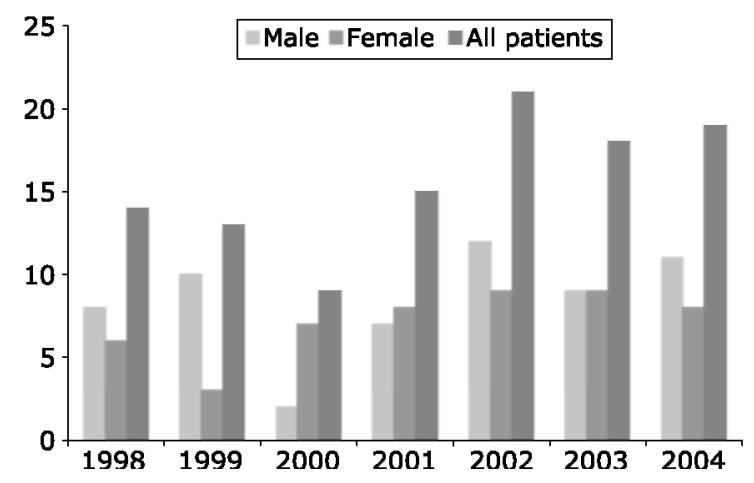

Analysis of the Belgian surveillance data indicated an average incidence of $1.6 \mathrm{sCJD}$ patient $/ 10^{6}$ inhabitants/year with a marked increase in the last 3 years $\left(\geq 1.8 / 10^{6} /\right.$ year) of our study, but this was found not to be significant (Figure 1). Next, we calculated age specific incidences using the following age groups (30-39 years, 40-49 years, 50-59 years, 60-69 years, 70-79 years, 80-89 years and above 89 years) using the data form this study and the average number of Belgian inhabitants in each age group for the study period (Data National Institute of Statistics). This calculation identified a highly increased incidence $\left(\geq 6.3 / 10^{6} /\right.$ year) between the ages of 70 and 90 years in the last 3 years of our study. This increase was significant $(p<0.01)$ when compared to the incidence found in the first 4 years of our study period or to the Belgian SCJD patients identified retrospectively between 1990 and 1997 (Figure 2a). This without a significant increase in the average age at death or there being a gender related difference. We did identify a similar significant rise if we calculated the incidence based on the total number of referrals to the surveillance system (Figure $2 b$ ).

Figure 2. (a) Comparison of the age group specific incidence of $s C J D$ in the 3 investigated periods. (b) Comparison of the age group specific incidence based upon the total number of referrals to the surveillance system in the 2 investigated periods.
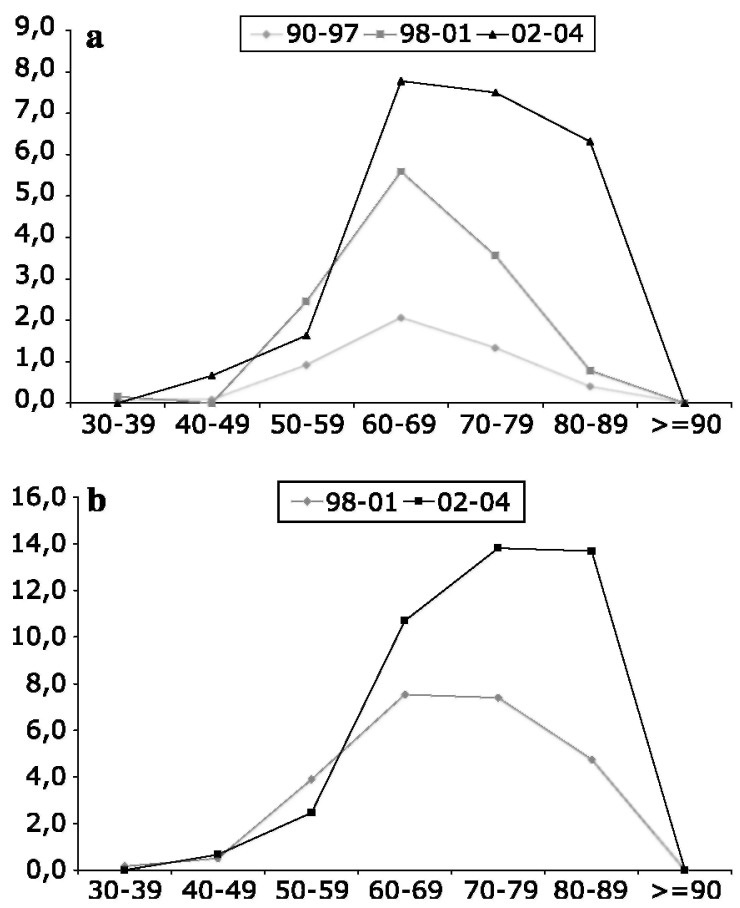
To explore this finding, we first investigated whether the sCJD patients over age 70 identified between 2001 and 2004 had a different phenotype or CSF biomarker levels compared to the other patients in our study or the retrospectively observed patients. The only significant difference was a decreased presence of pyramidal signs in the sCJD patients over 70 independent of the study period $(16 \%$ vs. $44 \%, p=0.04$; Table 1$)$. Also no significant difference was observed in the level and sensitivity of the CSF biomarkers (Table 1).

In order to further explore these populations we analysed the neuropathological lesion profile, the PrP129 and the PrP western blot type in 47 sCJD patients for whom sufficient material was available (Table 2). We observed no meaningful difference except for, a trend towards more MM1 patients in the most recent sCJD group over 70 .

During this investigation we also compared the neuropathological lesions of individual patients with the characteristic lesion profile of each CJD type. We found that one MV1 and two MM1 patients had severe neuropathological lesions in the thalamus, neostriatum and the brainstem areas and mild lesions in the cerebellum resembling the neuropathological lesion profile of the MV2 class but none had 'Kuru' type plaques. In another MM1 patient with prolonged disease duration of 14 months, we found severe lesions and PrP morula type plaques in all cortical areas and the cerebellum.

Table 1. Comparison of the clinical phenotype and CSF biomarker levels between the different studied periods and age groups. Next to the median and standard deviation of Tau and Amyloid-beta $(A \beta)$ also the sensitivity of 14-3-3 and tau (cutoff value $1300 \mathrm{pg} / \mathrm{ml}$ ) are shown

\begin{tabular}{|c|c|c|c|c|c|}
\hline & \multirow{2}{*}{$\begin{array}{c}90-97 \\
\text { all }(N=38)\end{array}$} & \multicolumn{2}{|c|}{ 1998-2001 } & \multicolumn{2}{|c|}{$2002-2004$} \\
\hline & & $\begin{array}{c}<70 \text { years } \\
(N=36)\end{array}$ & $\begin{array}{c}\geq 70 \text { years } \\
(N=13)\end{array}$ & $\begin{array}{l}<70 \text { years } \\
(N=33)\end{array}$ & $\begin{array}{c}\geq 70 \text { years } \\
(N=25)\end{array}$ \\
\hline Dementia & $100 \%$ & $100 \%$ & $100 \%$ & $100 \%$ & $100 \%$ \\
\hline Myoclonus & $77 \%$ & $90 \%$ & $83 \%$ & $81 \%$ & $91 \%$ \\
\hline Visual signs & $64 \%$ & $42 \%$ & $50 \%$ & $52 \%$ & $47 \%$ \\
\hline Cer & $87 \%$ & $90 \%$ & $82 \%$ & $86 \%$ & $62 \%$ \\
\hline Pyr* & $47 \%$ & $58 \%$ & $18 \% *$ & $27 \%$ & $16 \% *$ \\
\hline EPS & $57 \%$ & $40 \%$ & $45 \%$ & $44 \%$ & $45 \%$ \\
\hline Mutism & $75 \%$ & $71 \%$ & $80 \%$ & $44 \%$ & $48 \%$ \\
\hline EEG & $54 \%$ & $42 \%$ & $58 \%$ & $34 \%$ & $52 \%$ \\
\hline $14-3-3$ & $100 \%(N=2)$ & $94 \%$ & $90 \%$ & $94 \%$ & $92 \%$ \\
\hline Tau & $100 \%$ & $86 \%$ & $90 \%$ & $87 \%$ & $76 \%$ \\
\hline$(\mathrm{Pg} / \mathrm{ml})$ & $15870 \pm 8880$ & $9313 \pm 11359$ & $14209 \pm 11337$ & $5452 \pm 4885$ & $7239 \pm 7665$ \\
\hline $\mathrm{A} \beta(\mathrm{pg} / \mathrm{ml})$ & $244 \pm 42$ & $282 \pm 218$ & $273 \pm 212$ & $284 \pm 176$ & $335 \pm 225$ \\
\hline
\end{tabular}

Significant differences are indicated with an asterisk $(p<0.05)$. (Cer: cerebellar signs, Pyr: pyramidal signs, EPS: extra-pyramidal signs, EEG: presence of periodic sharp wave complexes in the electro-encephalogram).

Table 2. Comparison of the total sum of the three major neuropathological lesion in all examined brain areas between the PrP types

\begin{tabular}{lccccccc}
\hline Age group & \multicolumn{3}{c}{$<70$ years } & \multicolumn{2}{c}{$\geq 70$ years } \\
\cline { 2 - 8 } CJD type & MM1 & MM2 & MV1 & MV2 & VV2 & MM1 & MV2 \\
& $(N=25)$ & $(N=3)$ & $(N=3)$ & $(N=4)$ & $(N=2)$ & $(N=9)$ & $(N=1)$ \\
\hline Spongiosis & $18 \pm 2$ & $16 \pm 3$ & $18 \pm 1$ & $22 \pm 3^{*}$ & $19 \pm 1$ & $18 \pm 2$ & 18 \\
Gliosis & $15 \pm 3$ & $16 \pm 3$ & $17 \pm 1$ & $20 \pm 3^{*}$ & $19 \pm 1^{*}$ & $16 \pm 3$ & 19 \\
Neuronal loss & $15 \pm 3$ & $17 \pm 2$ & $19 \pm 1$ & $22 \pm 3^{*}$ & $18 \pm 1$ & $16 \pm 1$ & 18 \\
SynapticPrP & + & + & + & + & + & + & + \\
Peri-vacuolar PrP & + & + & + & + & + & + & + \\
(Kuru) plaque PrP & - & - & Kuru & Kuru & + & - & Kuru \\
\hline
\end{tabular}

Significant differences are indicated in bold and the asterisk $(p<0.05)$. 


\title{
Discussion
}

Our surveillance study identified an increased incidence of $\geq 1.8 \mathrm{sCJD}$ patients per million inhabitants per year in the most recent years in Belgium. This increase was most pronounced in the age groups between 70 and 90 years old (age specific incidence $\geq 6.3 / 10^{6} /$ year).

The Belgian CJD surveillance system, although voluntary, has identified one of the highest incidence figures in Europe. This is most likely due to a good coordination and following of the patients from clinical diagnosis to neuropathological confirmation. Also the existence of two independent databases contributes to smooth working of our system. We did agree in the beginning of the surveillance to only add probable and definite sCJD patients to the surveillance database because of the uncertainty of diagnosis and therefore strongly 'promote' an autopsy in patients suspected to have CJD (autopsy rate > 70\%).

In most European countries a similar increased incidence of sCJD was reported, especially in patients between age 60 and 80 (age specific incidence between 5 and 6/10\% /year) [20]. This finding is confirmed in our series although we obtained even higher incidence figures $\left(\geq 7.5 / 10^{6} /\right.$ year) in these age groups and also observed this increase in patients between 80 and 90 years (age specific incidence of 6.3/10\% $/$ year). Most likely this increase is due to more accurate and vigilant surveillance of CJD but to rule out any other possibility, e.g. a link to vCJD and BSE, we have further exhaustively studied our series using biochemical, neuropathological and molecular diagnostic tools.

The biochemical analysis of the 14-3-3 protein and tau in the CSF were shown to be sensitive markers for sCJD, independent of the age of the patient. Molecular diagnostic analysis showed our series to be similar to the previously reported SCJD populations [7, 11, 18, 21, 22]. Although molecular classification can be of use in surveillance projects, aberrations were detected by several authors [10, 18, 23] as well as in our series [24].

In conclusion, detailed analyses of our series only identified a lower rate of pyramidal signs in sCJD patients over age 70 whereas no further new pathological, biochemical or molecular characteristic could be identified. Nevertheless, our study indicates that increasing surveillance vigilance might lead to further increases in the incidence of SCJD in Europe as our series reveals an underestimation in patients over age 70.

\section{Acknowledgements}

The authors thank all physicians who sent us the CSF samples and clinical information of suspected CJD patients and control cases.

\section{References}

1. Masters CL, Harris JO, Gajdusek DC, Gibbs CJ Jr., Bernoulli C, Asher DM. Creutzfeldt-Jakob disease: patterns of worldwide occurrence and the significance of familial and sporadic clustering. Ann Neurol 1979; 5: 177-188.

2. Zerr I, Poser S. Epidemiology and risk factors of transmissible spongiform encephalopathies in man. Prions 2001; 7: 93-104.

3. Hill AF, Desbruslais M, Joiner S, Sidle KCL, Gowland I, Collinge J, et al. The same prion strain causes vCJD and BSE. Nature 1997; 389: 448-450.

\author{
4. Zerr I, Pocchiari M, Collins S, Brandel JP, Cuesta JD, Knight RSG, et al. Analysis of EEG and CSF 14-3-3 protein as aids to the \\ diagnosis of Creutzfeldt-Jakob disease. Neurology 2000; 55: 811-815.
}

5. Otto M, Wiltfang J, Tumani H, Zerr I, Lantsch M, Kornhuber J, et al. Elevated levels of tau-protein in cerebrospinal fluid of patients with Creutzfeldt-Jakob disease. Neurosci Lett 1997; 225: 210-212.

6. Van Everbroeck B, Green A, Pals P, Martin JJ, Cras P. Decreased levels of amyloid-beta in cerebrospinal fluid of Creutzfeldt-Jakob patients. J Alz Dis 1999; 1: 343-347.

7. Parchi P, Giese A, Capellari S, Brown P, Schulz Schaeffer W, Windl O, et al. Classification of sporadic Creutzfeldt-Jakob disease based on molecular and phenotypic analysis of 300 subjects. Ann Neurol 1999; 46: 224-233.

8. Collinge J, Hill A, Side K. Typing prion isoforms. Nature 1997; 386: 233-234.

9. Parchi P, Capellari S, Chen SG, Petersen RB, Gambetti P, Kopp N, et al. Typing prion isoforms. Nature 1997; $386: 232-234$. 
Published in : European Journal of Epidemiology (2006), vol. 21, pp. 443-447

Status : Postprint (Author's version)

10. Cardone F, Liu QG, Petraroli R, Ladogana A, D'Alessandro M, Arpino C, et al. Prion protein glycotype analysis in familial and sporadic Creutzfeldt-Jakob disease patients. Brain Res Bull 1999; 49: 429-433.

11. Alperovitch A, Zerr I, Pocchiari M, Mitrova E, Cuesta JD, Hegyi I, et al. Codon 129 prion protein genotype and sporadic CreutzfeldtJakob disease. Lancet 1999; 353: 1673-1674.

12. Pals P, Everbroeck BV, Sciot R, Godfraind C, Rob-berecht W, Dom R, et al. A retrospective study of Creutzfeldt-Jakob disease in Belgium. Euro J Epidemiol 1999; 15: 517-519.

13. Van Everbroeck B, Pals P, Dziedzic T, Dom R, Godfraind C, Sciot R, et al. Retrospective study of Creutzfeldt-Jakob disease in Belgium: neuropathological findings. Acta Neuropathol 2000; 99: 358-364.

14. Van Everbroeck B, Quoilin S, Boons J, Martin JJ, Cras P. A prospective study of CSF markers in 250 patients with possible CreutzfeldtJakob disease. J Neurol Neurosurg Psychiatry 2003; 74: 1210-1214.

15. Van Everbroeck B, Green A, Vanmechelen E, Vanderstichele H, Pals P, Sanchez-Valle R, et al. Phosphorylated tau in cerebrospinal fluid as marker for Creutzfeldt-Jakob disease. J Neurol Neurosurg Psychiatry 2002; 73: 79-81.

16. Van Everbroeck B, Pals P, Martin JJ, Cras P. Antigen retrieval in prion protein immunohistochemistry. J Histochem Cytochem 1999; 47: $1465-1470$.

17. Parchi P, Castellani R, Capellari S, Ghetti B, Young K, Chen SG, et al. Molecular basis of phenotypic variability in sporadic CreutzfeldtJakob disease. Ann Neurol 1996; 39: 767-778.

18. Hauw JJ, Sazdovitch V, Laplanche JL, Peoc' h K, Kopp N, Kemeny J, et al. Neuropathologic variants of sporadic Creutzfeldt-Jakob disease and codon 129 of PrP gene. Neurology 2000; 54: 1641-1646.

19. Van Everbroeck B, Croes EA, Pals P, Dermaut B, Jansen G, van Duijn CM, et al. Influence of the prion protein and the apolipoprotein E genotype on the Creutzfeldt-Jakob Disease phenotype. Neurosci Lett 2001; 313: 69-72.

20. Ladogana A, Puopolo M, Croes EA, Budka H, Jarius C, Collins S, et al. Mortality from Creutzfeldt-Jakob disease and related disorders in Europe, Australia, and Canada. Neurology 2005; 64: 1586-1591.

21. de Silva R, Ironside JW, McCardle L, Esmonde T, Bell J, Will R, et al. Neuropathological phenotype and 'prion protein' genotype correlation in sporadic Creutzfeldt-Jakob disease. Neurosci Lett 1994; 179: 50-52.

22. Kitamoto T, Dohura K, Muramoto T, Miyazono M, Tateishi J. The primary structure of the prion protein influences the distribution of abnormal prion protein in the central nervous system. Am J Pathol 1992; 141: 271-277.

23. Ironside JW, Head MW, Bell JE, McCardle L, Will RG. Laboratory diagnosis of variant Creutzfeldt-Jakob disease. Histopathology $2000 ; 37: 1-9$.

24. Zarranz JJ, Digon A, Atares B, Rodriguez-Martinez AB, Arce A, Carrera N, et al. Phenotypic variability in familial prion diseases due to the D178N mutation. J Neurol Neurosurg Psychiatry 2005; 76: 1491-1496. 